\title{
"Escovar a história a contrapelo”: uma reflexão sobre história e literatura em Beloved, de Toni Morrison
}

Anderson Borges

Mestrando em Teoria da Literatura / UFMG

\begin{abstract}
RESUMO
Neste texto reflito sobre a releitura ficcional de eventos ocorridos nos Estados Unidos presente em Beloved, de Toni Morrison, considerando a fecunda relação entre memória e imaginação, que, de certo modo, qual a figura do materialista histórico benjaminiano apresentado no texto "Sobre o conceito de história”, revela a história dos oprimidos.
\end{abstract}

PalaVRas-ChaVe

Ficção, memória, história, Toni Morrison, Walter Benjamin.

Veio para ressuscitar o tempo e escalpelar os mortos,

Veio para contar o que não faz jus a ser glorificado e se deposita, grânulo, no poço vazio da memória.

Carlos Drummond de Andrade

E se a memória mais não fosse que um produto da imaginação?

André Breton

“Nada do que um dia aconteceu pode ser considerado perdido”, afirma Walter Benjamin na sua terceira tese de "Sobre o conceito de história”. Parece conveniente associar esse pensamento a Beloved, livro escrito por Toni Morrison. Ao assumir o papel de contar a história dos escravos esquecidos este romance evoca, de certo modo, a imagem do “materialista histórico" benjaminiano, cuja missão é justamente salvar os oprimidos do esquecimento. Supondo de antemão que a ficção utilizando-se de elementos históricos possa 
produzir efeitos políticos na vida prática, resta a dúvida: seria possível que a literatura tomando o exemplo do romance Beloved - contribuísse em certa medida para lembrar dos esquecidos, tarefa então delegada ao historiador? Na tentativa de responder ou de pelo menos refletir sobre a pergunta proposta, aproximo o romance mencionado ao "materialista histórico” benjaminiano com a proposta de discutir a possibilidade da literatura revelar o escondido, idéia mencionada por Tzvetan Todorov; e, além disso, considerando que a literatura pode contribuir na formação de entendimento do mundo a partir da experiência literária do leitor, idéia proposta por Hans Robert Jauss.

Escrito em 1987, Beloved associa a dimensão do sofrimento e da humilhação vivida durante a escravidão à lenda e à magia do imaginário africano. O enredo tem lugar no contexto histórico logo após o fim da guerra civil americana. A ex-escrava Sethe - baseada na histórica Margaret Garner - prefere matar sua filha mais nova a retornar para a vida escrava. Em meio às descrições dos horrores a que se sujeitavam o povo negro, o fantasma da criança assassinada assombra a vida da ex-escrava Sethe e de sua filha Denver, as únicas que restaram de uma família que aos poucos vai se desfazendo.

Quando publicou Beloved, Morrison chegou a pensar que este seria seu trabalho menos prestigiado pelo público por abordar um assunto que mesmo atualmente deixa um gosto ruim na boca: a escravidão. Em entrevista, a autora afirma que esse tema é algo que "os negros não querem se lembrar, os brancos não vão querer se lembrar (...). É uma amnésia nacional.”

Num estudo minucioso sobre a memória histórica, Jacques Le Goff teoriza o conceito amnésia também no nível coletivo, ao afirmar que ela “é não só uma perturbação no indivíduo (...) mas também a falta ou a perda, voluntária ou involuntária, da memória coletiva nos povos e nas nações, que pode determinar perturbações graves da identidade coletiva”. ${ }^{2}$ Mais a frente, ele comenta sobre a memória coletiva posta em jogo pela luta das forças sociais pelo poder.

Tornar-se senhores da memória e do esquecimento é uma das grandes preocupações das classes, dos grupos, dos indivíduos que dominaram e dominam as sociedades históricas. Os esquecimentos e os silêncios da história são reveladores destes mecanismos de manipulação da memória coletiva. $^{3}$

\footnotetext{
${ }^{1}$ ANGELO citado por BOUSON, Whites might dirty her all right, but not her best thing. The Dirtied and Traumatized Self of Slavery, p. 131. (tradução nossa, bem como as seguintes.)

${ }^{2}$ LE GOFF. Memória, p. 421.

${ }^{3}$ LE GOFF. Memória, p. 422.
} 
A construção do passado no presente constitui muitas vezes um processo de disputas. Não é difícil perceber que a retificação da memória naturalmente assegura interesses políticos que muitas vezes preservam a perspectiva do vencedor.

Toni Morrison em Playing in the Dark: Whiteness and the Literary Imagination (Atuar no escuro: a cor branca e a imaginação literária) vislumbra na ficção estadunidense a imaginação em torno da figura do branco, uma verdade ainda então não revelada. Paralelamente ao criticismo literário, a autora aborda uma leitura da história a partir do imaginário americano revelando um importante aspecto negligenciado pela crítica: o homem negro. Morrison questiona a validade do conhecimento circulante entre os críticos e historiadores da literatura, o qual

(...) assegura que a literatura tradicional e canônica - desinformada e deformada pelos quatrocentos anos de presença - é livre de primeiramente africanos e em seguida de afro-americanos nos Estados Unidos. Ela presume que esta presença (...) não tem um lugar significativo ou uma consequência na origem e no desenvolvimento daquela literatura de cultura. ${ }^{4}$

Na direção oposta, a ficção de Toni Morrison presentifica a figura do negro de uma forma diferente daquela comumente apresentada na cultura norte-americana. Ao longo da literatura americana a representação estético-literária do negro servia como oposição ao ideal branco forjando, assim, o imaginário da indentidade americana. O negro na literatura de célebres autores estadunidenses como em Edgar Allan Poe, Herman Melville, Willian Faulkner, era o outro (the other). ${ }^{5}$ Em Beloved, observamos a ligação entre memória e imaginação - ligação estabelecida desde os gregos e que, após a separação na Idade Média, foi reencontrada de modo mais literário que dogmático no romantismo, como aponta Jacques Le Goff em História e memória.

Discutindo sobre as narrativas americanas que tematizam a escravidão, Morrison comenta que nenhuma sociedade que vivenciou essa triste página da história escreveu suficientemente sobre o assunto. Ela também observa que o gosto popular do século XIX

\footnotetext{
${ }^{4}$ MORRISON. Playing in the dark: whiteness and the literary imagination, p. 4-5.

${ }^{5}$ Devido ao propósito e às proporções deste texto não abordo questões relacionadas à identidade cultural, nem ao chamado folclore afro-americano; assuntos naturalmente suscitados pela leitura do romance estudado. Também não discuto a noção de "o outro", abordada largamente nos estudos culturais. Meu interesse aqui é reconhecer o valor da memória dos afro-americanos apresentada pela fição morrisoniana, relacionando-a à figura do historiador materialista apresentada por Walter Benjamin em suas teses de 1940. É preciso mencionar, ainda, que não abordo o aspecto messiânico da filosofia da história apresentada por Benjamin. Considero unicamente o efeito político de sua concepção, isto é, de que o historiador materialista não deve relegar os oprimidos ao esquecimento.
} 
“desencorajava” os escritores de escreverem sobre os "detalhes sórdidos” característicos da época. Havia uma espécie de convenção literária que evitava o “excessivo”, a "violência”, o “escatológico”. Era melhor jogar um “véu sobre aqueles procedimentos tão horríveis de serem relatados", comenta a autora. ${ }^{6}$

A contrapelo da perspectiva do passado, em Beloved como em outros romances seus, Morrison questiona o degradante poder de representações racistas, demonstrando o efeito do racismo internalizado na construção da identidade afro-americana. A ideologia de supremacia branca que se referia aos escravos estadunidenses como "a outra raça” norteia alguns dos principais tópicos abordados no livro. A descrição de traumas ${ }^{7}$ e humilhações a que os negros eram sujeitados constitui o cenário assombrado pelo fantasma da filha assassinada e percorrido pelos ex-escravos.

De modo lírico e emblemático, como usualmente o faz, Morrison reflete sobre a intenção de escrever o livro: “convidar os leitores (e a mim mesma) a entrar num cenário repulsivo (escondido, mas não completamente; deliberadamente enterrado, mas não esquecido) era armar uma tenda num cemitério habitado por fantasmas que falam alto.”8

Ainda no prefácio de Beloved, Morrison revela ao leitor seu desejo de encontrar personagens que pudessem manifestar a liberdade de uma forma comovente e arrebatadora e confessa que isso estava além do alcance de sua imaginação. No entanto, subitamente ela se lembra de um jornal resumindo a história de Margaret Garner, uma jovem mãe que após fugir da fazenda onde era escrava, foi presa por escolher matar um de seus filhos a entregá-lo ao trabalho escravo. A ausência de remorso chamou a atenção de abolicionistas e jornais da época. Sua obstinação em arriscar tudo pela liberdade ofereceu a Toni Morrison o mote para a construção da personagem tão desejada. Assim, surgiu Beloved, tal qual a "iluminação profana” de que fala Walter Benjamin no seu ensaio de 1929, “O surrealismo - o último instantâneo da inteligência européia”.

A escolha de tomar a figura histórica de Margaret Garner e seu contexto como matéria prima para o romance é justificada pelo fascínio então exercido na autora. O objetivo era adotar a historicidade verdadeira em sua essência, "mas não estritamente fatual com o fim de

\footnotetext{
${ }^{6}$ MORRISON citado por BOUSON. Whites might dirty her all right, but not her best thing. The dirtied and traumatized self of slavery, p. 133.

${ }^{7}$ Há uma extensa bibliografia relacionada ao trauma sofrido pelos negros na obra de Toni Morrison. para mais informações a respeito, consultar o livro de J. Brooks Bouson, Beloved. Quiet as it's Kept. Shame, trauma, and race in the novels of Toni Morrison, citado nas referências.

${ }^{8}$ MORRISON. Beloved, p. XVII.
} 
relacionar sua história a questões contemporâneas de liberdade, responsabilidade e o lugar das mulheres"9 . A heroína não aceitaria o terror e a vergonha a que os escravos e mesmo os exescravos, como no caso em questão, em geral eram subjugados. À justificativa da autora no prefácio do romance, é possível acrescentar o comentário de J. Brooks Bouson:

(...) acreditando que os senhores de escravos poderiam ter vencido se a experiência escrava estivesse para além de sua imaginação de escritora e de seus poderes romanescos, Morrison é determinada a tomar de volta a "autoridade" e o "poder" de contar a história dos escravos esquecidos. ${ }^{10}$

Aqui, é possível evocar um comentário da segunda tese de "Sobre o conceito da História” que vai ao encontro ao anseio de Toni Morrison, em que Benjamin pergunta: "Não existem, nas vozes que escutamos, ecos de vozes que emudeceram?”; ${ }^{11}$ e reconhece que o passado faz um apelo ao presente. Tal qual o materialista histórico, protagonista da historiografia redimida benjaminiana, a ficção, a sua maneira, é capaz de ouvir esse chamado.

Ora, a literatura pode lembrar as vozes dos fantasmas do passado, retomando as palavras da autora no prefácio de Beloved, já que a memória muitas vezes não se torna "história”, isto é, não é transmitida por alguns atores envolvidos (como é o caso dos escravos mortos e renegados ao esquecimento), nem pelas gerações seguintes (que devido à dor da lembrança abandonam a responsabilidade de transmitir), ou até mesmo porque os livros de história podem sancionar uma cadeia de acontecimentos que privilegia os vencedores - como debatem as novas teorias propostas pela historiografia contemporânea, sobretudo a partir da concepção da chamada "nova história"12 -, retomando a perspectiva benjaminiana anunciada na sua sexta tese de "Sobre o conceito da História”.

Em cada época, é preciso arrancar a tradição ao conformismo, que quer apoderar-se dela. (...) $\mathrm{O}$ dom de despertar no passado as centelhas da esperança é privilégio exclusivo do historiador convencido de que também os mortos não estarão em segurança se o inimigo vencer. E esse inimigo não tem cessado de vencer. ${ }^{13}$

\footnotetext{
${ }^{9}$ MORRISON. Beloved, p. XVII.

${ }^{10}$ BOUSON. Whites might dirty her all right, but not her best thing. The dirtied and traumatized self of slavery, p. 132.

${ }^{11}$ BENJAMIN. Sobre o conceito da História, p. 223.

12 Além da escola francesa, historiadores americanos, como Collingwood, Louch, Maurice Mandelbaum, Morton White, dentre outros, também contribuiram para a concepção de que "a história conta estórias”, ou seja, a história se constitui de narrativas. Para um detalhamento completo, ver o artigo de Louis O. Mink, "History and Fiction as Modes of Comprehension”, citado nas referências.

${ }^{13}$ BENJAMIN. Sobre o conceito da História, p. 224-225.
} 
A ficção ao ocupar-se de acontecimentos históricos que tornam possível trazer à tona memórias esquecidas possibilita “despertar no passado as centelhas da esperança”, impedindo que os mortos sejam esquecidos. Desse modo, a literatura, ao contrário do pretenso historiador neutro que representa o passado "tal qual ele foi”, pode confrontar a ordem estabelecida pelo esquecimento, apagamento ou controle do passado.

Esse "historiador neutro" é comentado nessa mesma tese formulada por Benjamin, em que ele logo no início critica a frase do prussiano Leopold von Ranke, cujo historicismo almejava conhecer o passado "como ele de fato foi”. O historiador historicista estabelece uma relação de empatia (Einfühlung) com o vencedor naturalmente confirmando a visão dos dominadores. Retomando o desfecho do fragmento citado, está claro que o inimigo de que fala Benjamin se bifurca em dois. De um lado, obviamente criticando a ascensão do partido nazista. De outro, o alvo é a socialdemocracia que assumia para si uma visão otimista do devir histórico (statt Revolution Evolution), contrária àquela benjaminiana que via na revolução "o correspondente profano da interrupção messiânica do devir histórico”.

O ensaio de Benjamin, com isso, não só reflete a crítica ao nazismo como também a cisão provocada na esquerda alemã durante a década de 1920 e, de certo modo, paradoxalmente, ainda mais acirrada na década de 1930, embora os representantes já se encontrassem no “exílio”. É possível, todavia, ampliar essa interpretação e compreender esse vencedor como aquele que renega a história dos vencidos ao esquecimento.

Através da ficção, a história desses oprimidos pode ser, em certa medida, retomada ainda que a partir da imaginação. Assim, considerando que a literatura pode contribuir na formação de entendimento do mundo a partir da experiência literária do leitor - argumento empregado pela estética da recepção jaussiana -, Beloved chama a atenção para a “esquecida” realidade da escravidão negra nos Estados Unidos.

Como se sabe, A história da literatura como provocação à teoria literária de Hans Robert Jauss procurou estabelecer uma nova concepção de história da literatura que fosse capaz de preencher a lacuna deixada na teoria literária pela crítica formalista e marxista. De um lado o formalismo, que embora tivesse considerado a evolução literária e o caráter sistemático constitutivo de cada momento, apresentava a história da literatura como uma sucessão de sistemas estético-formais. Do outro o marxismo, com a chamada "teoria do reflexo", contemplava a relação entre literatura e sociedade apenas no âmbito da representação. A estética da recepção jaussiana propõe completar uma "página em branco” deixada por ambas as escolas críticas considerando a literatura em sua historicidade. O teórico 
propõe que a historicidade da literatura se encontra na relação entre a história da literatura e a história geral, estabelecendo essa ligação de modo que a autonomia do caráter artístico não seja submetida à função meramente mimética e ilustrativa.

Assim, tendo em vista a relação literatura-história é possível verificar a formação de entendimento do mundo a partir da experiência literária do leitor. Dizendo de outra maneira, a leitura pode provocar no leitor o questionamento de ordens ratificadas por instituições sociais e/ou religiosas. Na argumentação jaussiana no desfecho do texto mencionado neste ensaio, “conclui-se que se deve buscar a contribuição específica da literatura para a vida social precisamente onde a literatura não se esgota na função de uma arte da representação"14.

Na esteira dessa concepção de que a literatura pode produzir um efeito na vida prática, Tzvetan Todorov no ensaio "Ficción y realidad” discute, conforme já aponta de antemão o título, o par ficção-realidade. O crítico russo traz à tona as cartas escritas por Américo Vespúcio sobre o chamado “continente novo”, Mundus novus e Quatuor navigatones. A riqueza imaginativa com que Vespúcio narra a realidade vista - embora hoje não seja possível ter certeza de que foi ele mesmo o autor daquelas obras - rendeu-lhe tanta fama e prestígio que o continente novo foi batizado com seu nome. Esse fato ilustra a chamada véritédévoilement, que revela ou desvela, proposta por Todorov como uma habilidade da ficção. Essa espécie de verdade se distingue da vérité-adéquation, i.e., aquela correspondente aos fatos, argumenta o crítico.

A descrição feita por Américo Vespúcio - se é que foi ele mesmo o autor das cartas certamente não revela uma imagem fidedigna à terra "recém-descoberta", mas foi mesmo assim capaz de mostrar ao leitor do século 16, bem como ao contemporâneo, a perspectiva do narrador/colonizador - ainda que ingênua e/ou idealizada, como atualmente pode se interpretar - a respeito das novidades vistas. As obras escritas por Américo Vespúcio, portanto, têm valor tanto histórico, quanto literário. Dessa forma, fica claro como a literatura em certa medida - então considerada em sua função constitutiva da sociedade - pode contribuir na formação do entendimento do mundo a partir da realização e da experiência literária.

Na última seção de "O narrador. Considerações sobre a obra de Nikolai Leskov" Walter Benjamin afirma que o narrador, tal qual o sábio, sabe dar conselhos, pois recorre à sua própria experiência e à dos outros. A última frase do ensaio é emblemática: “O narrador é

\footnotetext{
${ }^{14}$ JAUSS. A história da literatura como provocação à teoria literária, p. 57. (grifo do autor)
} 
a figura na qual o justo se encontra consigo mesmo.”15 Paralelamente ao clássico texto benjaminiano escrito em 1936, Toni Morrison ao apresentar seu discurso como ganhadora do prêmio Nobel de literatura em 1993 recorre a uma estória para falar sobre a importância de contar histórias.

A parábola contada por Morrison, como é característico desse tipo de texto, é simples e possui grande riqueza alegórica. Alguns jovens vão à casa de uma mulher cega, que conservava uma fama de ser sábia. Na versão que Morrison conhece - para explicitar ainda mais o caráter figurativo da estória - a mulher é negra e vive sozinha nos arredores de uma cidade nos Estados Unidos. Sabendo de sua cegueira, eles se aproximam dela segurando um pássaro e, a fim de testá-la, perguntam se ele está vivo ou morto. A mulher, depois de ter guardado silêncio, responde: "Eu não sei, eu não sei se ele está vivo ou morto, mas o que eu sei é que ele está em suas mãos, ele está em suas mãos.”16 Esta é a imagem central da parábola. Para Morrison essa mulher cega representa o escritor e o pássaro, por sua vez, figura a linguagem. A linguagem é, dessa forma, vista como um poder capaz de libertar. "Sua graça”, comenta a escritora, “está algumas vezes na transmissão da experiência”. Essa referência, consoante ao narrador benjaminiano, naturalmente anuncia sua concepção de literatura.

Ainda refletindo sobre a linguagem, Morrison ressalta que ela "jamais pode 'dizer exatamente’ a escravidão, o genocídio, a guerra. (...) sua força, sua felicidade está no seu toque em direção ao inefável”, ${ }^{17}$ tal qual é possível ler no romance Beloved, cuja estética não está assentada no modelo mimético realista e, dessa forma, não pretende dizer como exatamente foi a escravidão.

A relação amorosa entre Sethe e Paul D, dois ex-escravos que se encontraram alguns anos após a guerra civil americana; a incessante busca pela vingança do fantasma da filha assassinada pela mãe; o desprezo e a crueldade relacionada aos negros nos Estados Unidos pós-guerra de secessão; todos esses elementos constituem o enredo de Beloved. Talvez, o que mais chame a atenção do leitor nessa intensa narrativa, permeada por elementos históricos com poeticidade e vigor, seja a possibilidade de aproximar-se - mesmo através da ficção - da memória dos afro-americanos.

\footnotetext{
${ }^{15}$ BENJAMIN. Sobre o conceito da História, p. 221.

${ }^{16}$ Optei em fazer um tradução livre dos fragmentos citados. A estória contada por Toni Morrison bem como os comentários por ela feitos estão disponíveis no site oficial do prêmio Nobel, conforme apresentado nas referências.

${ }^{17}$ MORRISON. Beloved, p. XVII.
} 
No desfecho de sua Nobel lecture, ao nos convocar - nesse momento preciso naturalmente conjugar o verbo na primeira pessoa do plural - ao resgate da habilidade de contar histórias e compartilhar experiências, de maneira utópica Morrison compreende que a literatura - tal qual Jauss havia afirmado em sua crítica ao relacioná-la à história geral possui uma estreita conexão com a vida prática e pode, assim, influenciar no entendimento do mundo.

É plausível dizer que essa obra de Morrison pode ser pensada como uma "releitura" ficcional de eventos históricos distantes. Seguindo o exemplo da reflexão benjaminiana, que de maneira sui generis procura pensar a relação entre arte e sociedade, considerando o passado com vistas no presente, vejo no romance Beloved uma valiosa ligação entre o passado e o presente. Embora as pessoas que vivenciaram a escravatura obviamente não estejam mais aqui, a representação estética desses acontecimentos impede o esquecimento daquela barbárie e até mesmo evoca, em certa medida, considerações sobre aspectos políticos e sociais da sociedade americana atual - como o lugar do negro e da mulher, ou ainda, o lugar da mulher negra.

Essa “releitura” do passado e do presente se constrói em conformidade com uma tendência crescente a partir dos anos 1970, mais especificamente dos estudos culturais (Cultural Studies). Não é por acaso que em 1992, ano anterior ao da premiação de Morrison com o Nobel de Literatura, Rigoberta Menchú recebeu o Nobel da Paz por seu testimonio em Me llamo Rigoberta Menchú e así me nasció la consciencia (1983), obra na qual relata sobre as violências na Guatemala contra os povos Maia-Quiché). A diferença entre elas estaria no gênero: romance com teor testemunhal, no caso de Morrison, e relato de testimonio, no caso de Menchú. Mas, inegavelmente, ambas obras podem ser inseridas no contexto dos estudos culturais.

Retirando o véu que cobria o passado, Morrison constrói uma literatura como arte da memória e da imaginação. Se a memória dos oprimidos em algum momento não se tornou “história”, sua literatura não permite que as vítimas sejam esquecidas e além disso, novamente lembrando Benjamin, torna possível que o justo se encontre consigo mesmo.

\section{ABSTRACT}

In this text I reflect upon the fictional re-reading of events occurred in the U.S.A in the novel Beloved by Toni Morrison, considering the fertile 
relation between memory and imagination, which, in a certain way, similarly to the figure of the Benjaminian historical materialist presented in the text "Theses on the Philosophy of History," reveals the history of the oppressed.

\section{KEYWORDS}

Fiction, memory, history, Toni Morrison, Walter Benjamin

\section{REFERÊNCIAS}

BENJAMIN, Walter. Experiência e pobreza. In: Magia e técnica, arte e política: ensaios sobre literatura e história da cultura. Trad. Sérgio Paulo Rouanet. São Paulo: Brasiliense, 1985. p. 114-119. (Obras escolhidas, v. I)

BENJAMIN, Walter. O narrador. Considerações sobre a obra de Nikolai Leskov. In: Magia e técnica, arte e política: ensaios sobre literatura e história da cultura. Trad. Sérgio Paulo Rouanet. São Paulo: Brasiliense, 1985. p. 197-221. (Obras escolhidas, v. I)

BENJAMIN, Walter. O surrealismo - o último instantâneo da inteligência européia. In: Magia e técnica, arte e política: ensaios sobre literatura e história da cultura. Trad. Sérgio Paulo Rouanet. São Paulo: Brasiliense, 1985. p. 21-35. (Obras escolhidas, v. I)

BENJAMIN, Walter. Sobre o conceito da História. In: Magia e técnica, arte e política: ensaios sobre literatura e história da cultura. Trad. Sérgio Paulo Rouanet, São Paulo: Brasiliense, 1985. p. 222-232. (Obras escolhidas, v. I)

BOUSON, J. Brooks. Whites might dirty her all right, but not her best thing. The Dirtied and Traumatized Self of Slavery. In: . Beloved. Quiet as it's Kept. Shame, trauma, and race in the novels of Toni Morrison. New York: State University of New York Press, 2000. p. 131162.

GAGNEBIN, Jeanne Marie. História e narração em Walter Benjamin. São Paulo: Perspectiva, 1999.

JAUSS, Hans Robert. A história da literatura como provocação à teoria literária. Trad. Sergio Tellaroli. São Paulo: Ática, 1994.

LE GOFF, Jacques. Memória. In: SP: Editora UNICAMP, 1992. p. 419-476.

. História e memória. Trad. Irene Ferreira. Campinas,

LÖWY, Michael. Walter Benjamin: aviso de incêndio: uma leitura das teses "Sobre o conceito de história”. Trad. Wanda Nogueira Caldeira Brant. São Paulo: Boitempo, 2005.

MORRISON, Toni. Beloved. New York: Vintage, 2004.

MORRISON, Toni. Playing in the Dark. Whiteness and the literary imagination. London: Macmillan, 1993.

MORRISON, Toni. Nobel Prize in Literature. Disponível em: $<$ http://nobelprize.org/nobel_prizes/literature/laureates/1993/morrison-lecture.html>. Acesso em: 30 maio 2011. 
MINK, Louis O. History and fiction as modes of comprehension. In: COHEN, Ralph. New directions in literary history. London: Routledge and Kegan Paul, 1974. p. 107-124.

PADRÓS, Enrique Serra. Usos da memória e do esquecimento na história. Letras, n. 22: "Literatura e autoritarismo”, Santa Maria/RS, p. 79-95, jan./jun. 1991.

TODOROV, Tzetan. Ficción y realidad. In: Las morales de la historia. Trad. Marta Bertran Alcázar. Barcelona: Paidós, 1993. p. 119-144. 